PNL-SA--20849

DE92 015255

\title{
PULSE PORTABLE USABILITY LABORATORY SPACE ENVIRONMENT IN PROGRESS
}

A. Schur

May 1992

Presented at the

CHI '92, ACM Annual Conference on Human

Factors in Computing Systems

May 3-7, 1992

Monterey, California

Work supported by

the U.S. Department of Energy

under Contract DE-ACO6-76RLO 1830

Pacific Northwest Laboratory
Richland, Washington 99352

DISCLAIMER

This report was prepared as an account of work sponsored by an agency of the United States Government. Neither the United S.ates Government nor any agency thereof, nor any of their employees, makes any warranty, c press or implied, or assumes any legal liability or responsibility for the accuracy, completeness, or usefulness of any information, apparatus, product, or process disclosed, or represents that its use would not infringe privately owned rights. Reference herein to any specific commercial product, process, or service by trade name, trademark. manufacturer, or otherwise does not necessarily constitute or imply its endorsement, recom. mendation, or favoring by the United States Government or any agency thereof. The views and opinions of authors expressed herein do not necessarily state or reflect those of the United States Government or eny agency thereof.

United States Government or any agency thereof. 


\author{
PULSE \\ Portable Usability Laboratory Space Environment \\ in progress
}

Anne Schur

Pacific Northwest Laboratory 1

P.O. Box 999

Richland, Washington 99352

(509) 375.6488

WHAT: A "just-in-time" usability testing and diagnostic environment that can be used by both developer and user testing throughout the software life cycle.

The Portable Usability Laboratory Space Environment (PULSE) concept addresses the need to supply "just-in-time" usability testing to support the software developmant life cycle: requirements definition, ign, development, implementation, integration, technology transfer, operations and support. It is flexible and reconfigurable, a virtual space that can be molded to mimic a user's working environment. It is an environment in which tools for evaluating software applications can be placed. Thus testing can encompass not only the direct interactions between the user and the application software under test but also the impact of the surrounding environment.

PULSE uses portable partitions to derine the work space an individual would be expected to function in. Communication between user and tester can be achieved via headset and microphone. Data collection is achieved through traditional techniques such as video camera, remote and/or local observation of the user, and debriefing after test sessions. In addition, an on-line data collection and reporting tool which is being developed at Pacific Northwest Laboratory (PNL) is used. 'This User Software Evaluation Test Tool (USETT) resides 'on-top' of the application software under test.

USETT facilitates the collection of data from the perspective of each team member. Different disciplines have different priorities, different thinking systems, and different values. What some find valuable others do not even notice. And they do not notice that they do not notice.

From a developers viewpoint, quick context-related identification and capture of problems at all stages of the software development cycle is possible. USETT will support debugging and walkthrough activities at all levels of software engineering including low-level code development, software packaging, and integration. For users, interactive 'on-line' capture of their comiments via free form annotaticii and/or structured checklists and questionnaires is possible. Users' comments will be input and displayed at the location where the system behavior occurs. Additionally, new functions and enhancemerits to existing functions can be described at the desired location within an application.

1Operated for the United States Department of Energy by Battelle Memorial Institute under contract DE-AC06-76RLO 1830. 
WHY: Quick and available to a) meet product development cycles with limited time, funds and staff; b) meet environments with special security needs; and c) cut across organizational boundaries to facilitate user participation.

To create a user-centered system, thorough system testing by both developers (validation) and users (verification) must be performed throughout the life cycle of the software product. The last several years have seen the growth of usability test laboratories to meet the need of developing user-centered systems. However, the acquisition of such a laboratory may not be immediately feasible nor appropriate for the community which it will be expected to serve. At PNL the concept of PULSE is in development. It will be used to develop user-centered systems without requiring the establishment of a fixed usability test laboratory. This approach offers several immediate advantages.

A dedicated space is not needed to be acquired or equipped to perform usabillty testing functions, repeated use of PULSE in a cost effective and timely manner is possible, and many of the logistics of handling secure projects can be avoided. Also, software organizations are often structured to work against user and interdisciplinary team participation in the development of the product. PULSE, by its nature, encourages test participation and attendance by all those involved in the product across many organizations-- software cievelopers, users, and managers. For example, the USETT tool can share captured comments and allow new comments from different perspectives (software developers, users, managers, and marketing) to be added. These in-context collected comments can be used to discuss and make informed decisions for such issues as determining whether a schedule should be revised to accommodate an enhancement or addition of a capability.

The usability capability being developed at PNL is anticipated to serve a diverse customer base and audience. For example, the products developed at PNL include: automated supervisory control and monitoring systems for power systems, waste storage facilities, and robotic waste sample preparation systems, maintenance and diagnostic systems, software user manuals, and user-friendly front-ends that serve as gateways into complex information management systems and/or data repositories.

BENEFITS: A single integrated environment for development and user acceptance testing of any application software.

- Tests the complete system and not its pieces

- Access by development team and users is easy

- Facilitates 'cross-over' between organizations

- Integrates the team in the design process

- Collects data from the perspective of each team mer.iber

- Is re-usable and possible to have more than one

- Keeps up witin rapid product development

- Focuses user training programs including documentation and hands-on training

- Results in cost saving by stream-lining life cycle development and product support. 
ISSUES: The current approach taken at PNL raises many questions and changes the focus of usability testing. To some, the approach is considered a first step toward usability engineering.

- When snould a dedicated usability laboratory be developed and used?

- When is a usability test specialist necessary during the software life cycle?

- How much does this approach move beyond testing just the user-computer interface?

- What impact will this approach have on the traditional software development life cycle.

ACKNOWLEDGEMENTS: The development of the proof-of-concept USETT protoiype was internally funded by Facific Northwest Laboratory and developed using Silicon Beach Software's SuperCard and hosted on a Macintosh llfx, with a RasterOps 17 inch monochrome $1024 \times$ 768 resolution monitor. 
7
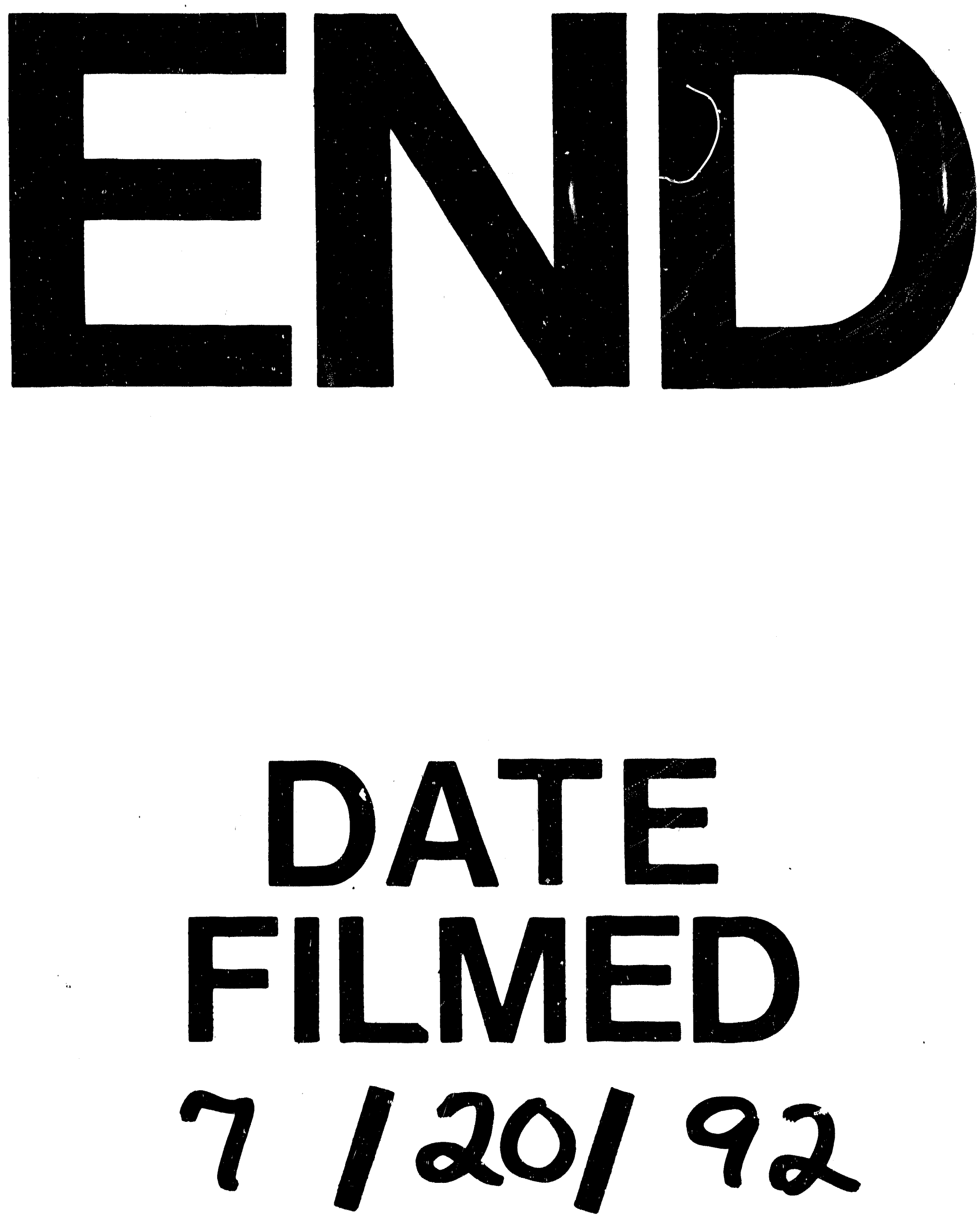


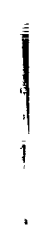

